\title{
THE POSSIBLE SIMILARITY BETWEEN ORGANIC SUBSTANCES IN LEACHATES AND FOREST WATERS
}

\author{
Staffan Agren, PhL \\ The Ragnar Sellberg Foundation, Högbytorp, 19793 Bro, Sweden
}

\begin{abstract}
It is nowadays recognised that natural organic substances have a large impact on processes in different environments. This recognition is developing also with respect to organic substances in municipal landfill leachates. There is reason to look for chemical similarities and take over useful analysis tools and concepts from forest research to speed up the build-up of knowledge of such compounds in leachates. It has been observed at a large number of forest sites that organic substances in general tend to have similar properties. The key to possible similarity between leachates and forest waters seems to be the humic substance fraction. They are abundant already in today's methanogenic leachates, and their influence will increase in the course of time. Observed interactions confirm that increased understanding of the character of humic substances is important in studies of most other compounds in leachates.
\end{abstract}

\section{KEYWORDS}

Organic substances, humic substances, municipal landfill, leachate, forest water, pollutant.

\section{BACKGROUND}

Natural organic substances are to some extent present in all geological (soils, sediments) and pseudo-geological (e. g. municipal landfills) systems. Like other organic substances, they basically contain the chemical elements carbon, hydrogen, oxygen, and to a smaller extent nitrogen and sulphur. Their origin is dead cell materials and metabolic output products from plants and organisms. In the solid phase, they occur in accumulation areas like bogs, marshes, fens, muds, podzols, brown earth soils, lake and sea sediments, as well as landfills. In soil waters, groundwaters, surface waters, and leachates, they may take the form of suspended or colloidal particles, macro-polymers or simple low-molecular substances (in free form anions).

In these varying forms, and under influence of $\mathrm{pH}$, redox and microbes, they take part in many processes and tend to significantly influence the conditions of their environments by important interactions. For instance, we know that organic substances may

- counteract acidification of natural waters by acid-base buffering, cation exchange, and liberation of buffering cations from rock and soil minerals.

- influence soil formation and bioavailability of nutritional and hazardous metals by mobilising or demobilising them in different ways. 
- form clay-humus aggregates in soils, which improve the particle structure in relation to air, water and root penetration.

- degrade or absorb man-made organic toxicants.

- generate chloro-organic toxicants in drinking water and soil pore waters.

- alter surface tension and diminish light absorption, which changes the life conditions of many organisms in the near-surface zone of natural waters.

More basics can be read in, e. g., (1), (2), (3), as well as many other sources.

Because of their complex character, organic substances were earlier put in a "black box" or simply not taken into account in studies of natural chemistry. However, the effects listed here show that they may be of considerable importance in many biogeochemical processes. One can suspect that measurements of inorganic substances not considering these influences in practice may include effects of interactions with organic substances. If such effects become interpreted as purely inorganic, this will give misleading information about the objects and processes studied and likely cause the wrong conclusions.

The erroneous neglecting of natural organic substances is nowadays well recognised. Still it remains a difficult task to fully understand and agree on their contribution to different processes. This statement is certainly valid not only for natural environments but even more for landfills where, in comparison, research with a high level of detail resolution as concerns the whole mixture of organic substances is much more difficult to find.

In this situation, it is worthwhile to consider bridging between research on natural organic substances and organic substances in landfills to enhance the build-up of knowledge in the latter subject area. The need of pollutant reduction makes systematisation of knowledge that includes applicable aspects from forest waters especially important for leachates. In addition, the introduction of wetlands, land areas with energy crops etc. in leachate treatment gives further reason to incorporate knowledge of organic substances in natural or nature-like systems, developed in other connections.

The gain in looking for similarities between organic substances in leachates and natural waters is obvious. Such similarities would motivate integration of useful concepts, tools, and findings, mostly not yet considered in leachate research. Furthermore, focusing on similarities also includes the opposite aspect and may result in better recognition of factors unique to leachates.

Is similarity possible in complex natural systems? An elucidating example: though human beings and flies certainly look very different, we find a DNA that is astonishingly similar. Shifts in relatively few segments of the DNA string are enough to cause a total change in appearance and behaviour. Thus, finding similarity depends on the level and purpose of our study and is not necessarily hindered by the total complexity of the focused system.

\section{AIM AND DELIMITATION}

The aim of this paper is to elucidate and discuss to what extent there is reason to believe that organic substances in leachates are similar to those in forest waters. The term natural waters is here delimited to forest waters, which includes soil waters, groundwaters, streams and lakes. 


\section{MATERIALS AND METHODS}

In forest waters, concentrations of organic substances are measured as total organic carbon (TOC), where dissolved organic carbon (DOC) is the fraction of TOC passing through a $0.45-\mu \mathrm{m}$ standard filter. The remainder, caught by the filter, is called particulate organic carbon (POC). It can be assumed that DOC, besides polymers, macromolecules and defined low-molecular ions, consists of 20 to $200 \mathrm{~nm}$ large colloid particles or aggregates (4). This multi-character makes it possible to apply both solvent chemical and surface chemical analysis tools on DOC and gives an insight into the great complexity of these substances.

Leachate samples from the Högbytorp landfill at Bro, $40 \mathrm{~km} \mathrm{NW}$ of Stockholm, were collected directly from a storage basin, an aerated basin, and the outlet of a settlement basin, and from a proportional flow collection device at the earlier used outlet to the sewage treatment plant Käppalaverket. An ordinary spectrophotometer and a commercial carbon analyser measured UV absorbance and DOC concentration in the leachate samples.

Sampling and analysing methods behind other findings mentioned in this paper are best described by the sources referred to in the reference list.

\section{WHAT IS KNOWN TODAY?}

\section{Organic substances in forest waters}

This description is to a great extent taken from (5). Reported concentrations of organic

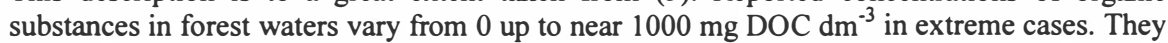
are divided into hydrophobic and hydrophilic acids, neutrals, and bases. Acids tend to dominate.

In the hydrophobic fraction we find the humic substances, by definition adsorbed on the surface of XAD-8 column materials. As a rule of thumb, this fraction contains about $50 \% \mathrm{C}$ by weight. It is divided into humin, humic acids and fulvic acids, of which the two first categories are more aromatic and high-molecular with fewer acidic groups than the last category. The conventional way of isolating these categories from each other is to precipitate humic acids at $\mathrm{pH} \mathrm{1,} \mathrm{while} \mathrm{fulvic} \mathrm{acids} \mathrm{remain} \mathrm{dissolved} \mathrm{at} \mathrm{low} \mathrm{as} \mathrm{well} \mathrm{as} \mathrm{high} \mathrm{pH}$ levels. Humin has a very low solubility and is of little interest in natural waters.

Among the hydrophilic (non-humic) substances, one can find more well-defined lowmolecular acids, polypeptides, amino acids, polysaccharides, lipids and fats. It is known that soil organisms (microbes, lichens, and fungi) actively secrete low-molecular substances like oxalic acid, and citric acid, as part of their metabolism. However, microbes easily degrade such substances. Findings in forest waters indicate the importance of metal-binding carboxyl groups that are part of more persistent aliphatic chains connected to a base core of aromatic units (5).

\section{Organic substances in municipal landfill leachates}

Much of the information in this section is fetched from the valuable data compilation made by (6). To begin with, municipal landfill leachates normally contain little suspended material.

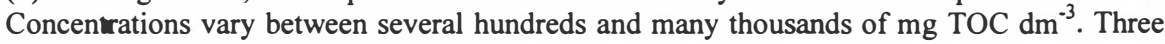
main fractions reported are volatile low-molecular organic acids, humin, and humic and fulvic acids. 
In the first fraction, we find significant amounts of fatty acids (mostly acetic, propionic and butanic acids), alcohols, proteins, amino acids, benzenes, phenols, oil and grease, and halogenated compounds. The proportion of fatty acids can be extremely large in the acidogenic landfill phase. Over 250 defined organic compounds have been listed. However, a general characterisation method has been developed (7), which improves management of pollutant control in leachates, especially for the mixture of well-defined organic substances.

The second fraction is small and constitutes up to $5 \%$ of the total organic content in the acidogenic phase, while it almost disappears in the methanogenic phase. Evidently, the third fraction of humic and fulvic acids becomes more important in the methanogenic phase.

Recognition of the large number of man-made materials and compounds like plastics with additives, flame-retardants etc., and the extreme variety of metals in landfills, gives a hint that leachates have the potential to be even more complex than common forest waters. However, it should be noted that, also in forest soils, there is a production of substances like chlorinated hydrocarbons.

In addition to the large number of problematic organic substances, municipal landfill leachates tend to contain large concentrations of salts (mainly $\mathrm{NaCl}$ ) and nitrogen $\left(\mathrm{NH}_{4}-\mathrm{N}\right)$. It is noteworthy that heavy metal concentrations $(\mathrm{Hg}, \mathrm{Cd}, \mathrm{Pb})$ in municipal landfill leachates normally fall below drinking-water standards. Since the amount of sulphur estimated in the Högbytorp landfill cannot keep more than $5 \%$ of the heavy metals in the form of sulphides (8), it is evident that interactions with solid organic matter, and perhaps also Fe (II) compounds, have to explain most of the metal fixation. If oxygen in a later stage succeeds to penetrate the waste, furthered breakdown of organic matter, formation of colloidal Fe (III) hydroxides, and finally also exhausted buffering, can be expected to cause significant metal mobilisation (9).

One lately more observed aspect on contaminant transport in leachates and natural waters is the role of colloids. In the presence of oxygen, amorphous iron hydroxides as well as humic substances tend to interact with each other in colloidal form. Under anaerobic conditions, the role of iron diminishes while the humic fraction still remains important. A study of the sorption of halogenated hydrocarbons like dichloromethane, tetrachloromethane, 1,4dichlorobenzene, 1,2,4-trichlorobenzene, hexachloro-1,3-butadiene, and hexabromo-benzene, to humic colloid particles in the Högbytorp leachate (10) showed that colloids act as carriers that contribute to more than $50 \%$ of the mobilisation of these substances from the landfill.

\section{ANALYTICAL TOOLS}

\section{The concentration of organic substances}

Biological oxygen demand (BOD) and chemical oxygen demand (COD) are the parameters traditionally used to measure concentrations of organic substances in leachates. Especially $\mathrm{BOD}$ and $\mathrm{BOD} / \mathrm{COD}$ ratios give valuable input regarding the difficulty to degrade the organic substances, the supply of carbon source in denitrification, or the maturity phase dominating the landfill. However, this makes it problematic to compare concentrations of organic substances in leachates with those in forest waters, since TOC and DOC are the parameters used in the latter waters. BOD and COD mirror operationally defined fractions of the organic substances, while TOC and DOC per definition include the total carbon content.

Table 1 shows that TOC and COD are directly connected (this is of course expected), the TOC/COD ratio increases when TOC increases (the COD fraction seems more difficult to mobilise than other organic fractions), and COD decreases when the leachate flux increases 
(increased flux engages coarser transport pores with little COD which dilutes the total COD). This exemplifies the use of introducing TOC and DOC as standard parameters, which after some years will give a valuable data series and make comparison with other leachates and waters easier.

\begin{tabular}{|l|l|l|l|}
\hline Parameter $\mathbf{X}$ & Parameter $\mathbf{Y}$ & Coefficient & Statistical significance \\
\hline TOC & COD & $r \mp 0.63$ & $p<0,1 \%$ \\
TOC & DOC/TOC & $r \mp-0.22$ & None \\
TOC & TOC/COD & $r F 0.48$ & $p<2 \%$ \\
Leachate flux & COD & $r \mp-0.68$ & $p<0,1 \%$ \\
Leachate flux & TOC & $r=0.31$ & None \\
\hline
\end{tabular}

Table 1. Correlations coefficients ( $r$ ) for linear regression calculations involving TOC, DOC, COD, and leachate flux, from control measurements at the Högbytorp landfill during March 1997 to February 1999 ( $n=24$, one sample per month).

\section{UV and visible light absorption}

UV and visible light absorption (absorbance) is an analytical parameter that has been extensively used in studies of humic substances and organic carbon in forest waters. In leachate research, such data seem to be very rare. This method depends on the light absorption by conjugated carbons, which favours response by aromatic organic structures. UV absorbance is normally measured at 250 or $254 \mathrm{~nm}$. The so-called $E_{4} / E_{6}$ ratio, which is visible light absorption at the wave length of $465 \mathrm{~nm}$ related to the one at $665 \mathrm{~nm}$, is commonly used to indicate molecular size and aromaticity in comparative studies.

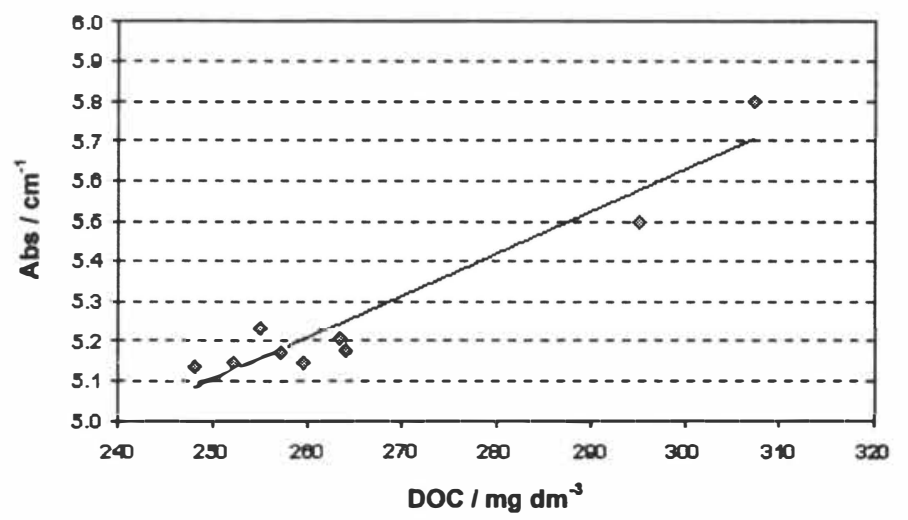

Figure 1. UV absorbance at $250 \mathrm{~nm}(\mathrm{Abs})$ as a function of DOC in leachate samples collected at three occasions in August and September 2000. The regression line is $Y=0.011 X+2.46\left(n=9, r=0.96^{* * *}\right)$.

Figure 1 illustrates the UV absorbance in leachate samples from the Hogbytorp landfill. Regressions show that UV absorbance in relation to DOC, on the average, corresponds to 20 $\mathrm{cm}^{2} \mathrm{mg}^{-1}$, which is $65 \%$ of the same average ratio in DOC-rich pore waters from organic 
topsoil materials at 17 different forest sites (5). The indication is that organic substances in a leachate from a methanogenic landfill contain a smaller share of aromatic compounds than forest waters. Reasons may be a smaller concentration of lignin derivates than in natural waters from woodlands (i. e. a lower share of aromatic compounds in the humus fraction), or maybe a significant concentration of fatty acids still remaining after the acidogenic phase.

\section{Fractionation by XAD-8 resins}

Acidification of samples to $\mathrm{pH} \mathrm{1,} \mathrm{fixation} \mathrm{of} \mathrm{organic} \mathrm{substances} \mathrm{on} \mathrm{an} \mathrm{XAD-8} \mathrm{resin,} \mathrm{and}$ elution of these substances by strong base, gives the hydrophobic fraction. This is the official instrumental definition of the fraction of humic substances.

Analyses of three replicates from the Högbytorp leachate, at one occasion made with such a resin (11), showed that the hydrophobic fraction of TOC was $43 \%$. This is somewhat lower than the $50 \%$ normally found in forest waters. Still it is large in comparison with several other landfills where the shares were $15-40 \%$ (11). However, it seems likely that the smaller relative UV absorbance in the Högbytorp leachate in comparison with forest waters at least to some part was due to non-aromatic fatty acids.

\section{Other analytical tools}

Besides the analytical tools mentioned above, researchers, not least those interested in humic substances, have applied a large number of methods to analyse organic substances in forest waters. Examples may be potentiometric and other kinds of titrations, batch-studies of kinetic or equilibrating processes, many different ways of creating "controlled" chemical and thermal disintegration, studies by NMR, ESR as well as IR and photon correlation spectroscopy, measurements of viscosity and colligative properties, scattering, gel chromatography, gas chromatography, liquid chromatography with mass spectrometry, electrophoresis, electron microscopy etc.

\section{Recommendations}

It is evident that many analytical parameters are available. Using several of them in combination is motivated, since a larger number of aspects are needed to catch the basic character of organic substances. The suggestion is to add primarily TOC and DOC, and UV absorbance at $250 \mathrm{~nm}$, as standard parameters in landfill control programmes. Other more complicated analyses like XAD-8 fractionations, acidity, and ability to bind metals, are better performed in special projects. For improved strategy and design of leachate measurements in general, and for defined organic compounds in particular, it is recommended to read (7).

\section{IS SIMILARITY POSSIBLE?}

\section{Findings in forest waters}

DOC properties were studied in 23 forest waters that were either directly sampled, taken from lysimeters, or collected by centrifugation of organic materials from topsoils at Swedish and Danish forest sites (5). With one exception, no qualitative differences were significantly related to sampling along the geohydrological gradient, or tree species (spruce, pine, beech, birch), mineralogy (poor, intermediate, rich), and clear-cutting policy (stem harvest vs. wholetree harvest). Similarity was especially pronounced for properties like acid-base buffering, titrated acidity, strength of Al-DOC binding, and average-weight molecular weight. In no case, UV absorbance at $250 \mathrm{~nm}$ was found to depend on $\mathrm{pH}$. 
The observed similarity was in good accordance with other investigations also using cautious investigation methods. The large data variation resulting from the inclusion of all kinds of studies seems to reflect widespread use of manipulative and questionable treatment methods rather than real molecular differences.

\section{Extending similarity to leachates}

Similarity between forest waters and leachates seems possible, since

1) essential organic building elements differ much less from each other than the composite compounds they build up.

2) solubilisation tends to favour fractions with certain properties in common.

3) preferential degradation furthered by microbes eliminates non-persistent substances and accumulates a refractory fraction with less varied and more elementary structures.

4) transformation of intermediate species during degradation, or condensation of small labile organic molecules, result in refractory substances with a more uniform character.

Explanation 1) takes us back to the DNA example: disintegrating the complex chemical structure that creates life exposes the relative simplicity of its components. The secret of complexity is the precise co-arrangement of a large number of relatively simple components.

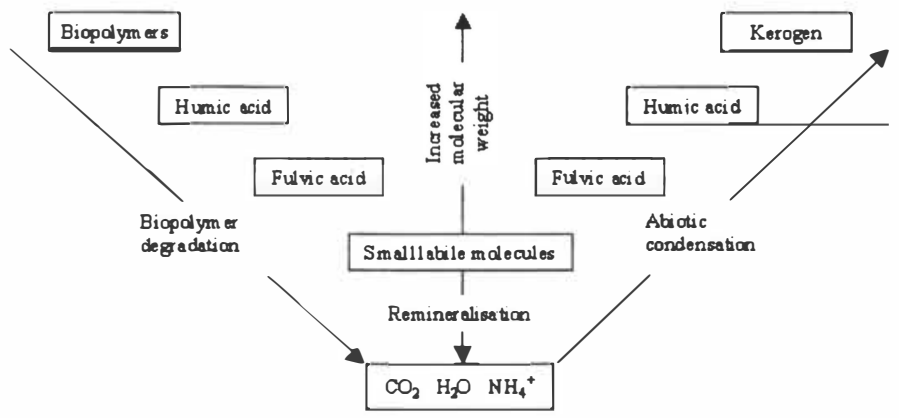

Figure 2. Schematic representation of two main theories for the formation of humic substances: biopolymer degradation and abiotic condensation (12).

Explanation 2) infiers that dissolved organic substances have to be more alike than their solid precursors due to the fact that they more easily become dissolved.

Explanations 3) and 4) can be related to the two main theories of humus formation that are illustrated in Figure 2. Independent of theory, their implication is that development in the direction of similarity is closely connected with increasing dominance of the humus fraction. The longer the course of time, the more will preferential degradation, transformation and integration reduce the non-humic fraction.

What we can expect is a process of convergence, reflected by more aromatic structures, larger average molecular weights, more hydrophobic behaviour, fewer functional groups, and metal blocking of remaining functional groups. Thus, initially starting from a wide variety of 
organic source materials, humification continuously increases homogeneity in the direction of a set of similar refractory end-products.

\section{CONCLUSIVE SUMMARY}

Similarity between organic substances in leachates and forest waters is connected with the humic substance fraction and the time perspective involved. Since humic substances are part of leachates in today's methanogenic phase, they already have an impact towards similarity. This process will slowly accelerate and reach its highest levels when the humus phase replaces the methanogenic phase.

There would likely be a gain in using more of the analytical tools and concepts applied on organic substances in forest waters also in leachate research. Insights in leachate chemistry and comparisons over a wider knowledge area would be improved, both in terms of elucidating similarity and dissimilarity. Not least, observed interactions between humic and inorganic (metals) as well as other organic substances (persistant organic pollutants) confirm that increased understanding of humic substances is important in studies of most other elements and compounds in leachates.

\section{REFERENCES}

1. Stevenson, F.J. (1982). Humus Chemistry. Genesis, Composition, Reactions. WileyInterscience, Chichester etc.

2. Haze, M.B.H., MacCarthy, P., Malcolm, R.L., Swift, R.S. (1989). The search for structure: setting the scene. In: Haze, M.B.H., MacCarthy, P., Malcolm, R.L., Swift, R.S. (Eds.): Humic Substances II. In search of structure. Wiley-Interscience Ltd, Chichester, pp. 3-31.

3. Glaze, W.H. (1990). What is the composition of organic acids in aquatic systems and how are they characterised? In: Perdue, E.M., Gjessing, E.T. (Eds.): Organic Acids in Aquatic Ecosystems. Life Sciences Research Report 48, Wiley-Interscience, Chichester, pp. 75-95.

4. Cačeči, M.S., Moulin, V. (1989). Investigation of humic acid samples from different sources by photon correlation spectroscopy. In: Allard, B., Borén, H., Grimvall, A. (Eds.): Humic Substances in the Aquatic and Terrestrial Environment. Lecture Notes in Earth Sciences, Springer Verlag, pp. 97-104.

5. Ågren, S. (2001). Properties of dissolved organic carbon and aluminium mobilisation in waters from Swedish and Danish forest sites. Licentiate Thesis, Dept. of Physical, Inorganic and Structural Chemistry, Stockholm University, Stockholm, Sweden.

6. Kylefors, K. (1999). Leachate quality and treatment. In: Lagerkvist, A. (Ed.): Landfill technology. Report 99:1, Division of Landfill Science \& Technology, Luleå Technical University, Sweden, pp. 9:1-9:89.

7. Öman, C., Malmberg, M., Wolf-Watz, C. (2000). Development of methods for the characterization of leachates from landfills. IVL Swedish Environmental Institute Ltd. RVF Development Drive within Landfilling, Report No. 3 (in Swedish with English abstract).

8. Aulin, C., Neretnieks, I. (1995). Material balance for an industrial landfill. In: Christensen, T.M., Cossu, R., Stegmann, R. (Eds.): Siting, lining, drainage and landfill mechanics. Proceedings Sardinia 95. Vol. III. CISA, Via Marenge 34, I-09123 Cagliari, pp. 173-180. 
9. Mårtensson, A., Aulin, C., Wahlberg, O., Ågren, S. (1999). The effiect of humic substances on the mobility of toxic metals in a mature landfill. Waste Management and Research, 17, pp. 296-304.

10. Brücher, J., Öman, C., Bergström, L. (1999). Sorption of halogenated hydrocarbons to colloidal organic material in a landfill leachate. In: Brücher, J.: The influence of sorption on transport of organic compounds in soil. Paper IV, Doctoral Thesis, Div. of Water Quality Management, Dept. of Soil Sciences, SLU, Uppsala, Sweden, pp. 1-14.

11. Welander, Ulrika (1994). Unpublished data from Högbytorp and other Swedish landfills. Present affiliation: Dept. of Biotechnology, Lund University.

12. Hedges, J.I. (1988). Polymerization of humic substances in natural environments. In: Frimmel, F.H, Christman, R.F. (Eds.): Humic substances and their role in the environment. Life Sciences Research Report 41, Wiley-Interscience, Chichester etc., pp. 45-58. 